\title{
Analytics for Knowledge Creation: Towards Epistemic Agency and Design-Mode Thinking
}

\author{
Bodong Chen \\ University of Minnesota, USA \\ chenbd@umn.edu \\ Jianwei Zhang \\ University at Albany, SUNY \\ jzhang1@albany.edu
}

\begin{abstract}
Innovation and knowledge creation call for high-level epistemic agency and designmode thinking, two competencies beyond the traditional scopes of schooling. In this paper, we discuss the need for learning analytics to support these two competencies, and more broadly, the demand for education for innovation. We ground these arguments on a distinctive Knowledge Building pedagogy that treats education as a knowledge-creation enterprise. By critiquing current learning analytics for their focus on static-state knowledge and skills, we argue for agency-driven, choice-based analytics more attuned to higher order competencies in innovation. We further describe ongoing learning analytics initiatives that attend to these elements of design. Prospects and challenges are discussed, as well as broader issues regarding analytics for higher order competencies.
\end{abstract}

Keywords: Innovation, knowledge building, learning analytics, agency, choice

\section{INTRODUCTION}

... in order to bring education into line with the needs of society, it would be necessary to undertake a complete revision of the methods and aims of education, rather than continue to be satisfied with simple appeals to common sense. (Piaget, 1972, p. 16)

Innovation is key to sustainable economic growth and solutions to complex problems in knowledge or innovation-driven societies (OECD, 2004). What can schools, from kindergarten to tertiary level, do to increase a society's capacity for innovation? This is one central question that motivates numerous " $21^{\text {st }}$ century skills" initiatives worldwide (e.g., Binkley et al., 2012). Current education systems, as criticized by some innovators and experts, tend to keep students on predetermined paths to master given knowledge and skills instead of fostering serendipity, risk-taking, choice-making, failure, and long stretches of work (National Academy of Engineering, 2015); to meet increasing demands for innovation, K-12 education needs to "create a pedagogy, class, framework, or method where students learn from their mistakes without being penalized" and to "encourage creative ideas even if there is no short-term return or fruition of the idea" (pp. 51-52). In essence, in order to nurture creative talents, alternative education paradigms are needed to bring education into closer alignment with innovative practices. 
(2016). Analytics for knowledge creation: Towards epistemic agency and design-mode thinking. Journal of Learning Analytics, 3(2), $139-163$. http://dx.doi.org/10.18608/jla.2016.32.7

While "education for innovation" is gaining increasing attention, learning analytics - a nascent field aspiring to optimise learning and teaching by discovering actionable knowledge from educational data (Long \& Siemens, 2011) - has yet to invest much in it. This situation is not surprising, since assessment regimes wherein many learning analytics projects are developed stress content standards and education accountability, with the acquisition of static facts and routine skills treated as the main, if not sole, learning outcome (Schwartz \& Arena, 2013). Higher order competencies essential to the dynamic and adaptive aspects of innovation - such as curiosity, resilience, and "way-finding" in complex spaces (Deakin Crick, Huang, Ahmed Shafi, \& Goldspink, 2015; Dweck, 2006; Lawless, Mills, \& Brown, 2002) are sidelined in formal education and thus also in learning analytics projects. Despite the popular argument that people need to have the basics in order to innovate, learning analytics ${ }^{1}$ that directly deal with high-order competencies conducive to innovation are urgently needed.

In this paper, we argue that learning analytics should contribute to the challenge of fostering education for innovation in knowledge societies. To this end, we first highlight design-mode thinking driven by high-level epistemic agency as two central aspects of innovation. Drawing on decades of work on Knowledge Building (Scardamalia \& Bereiter, 2003, 2014) - a distinctive educational approach to support education for innovation - we discuss design principles of analytics for innovation and knowledge creation. We present current analytics initiatives aiming to facilitate design-mode thinking and epistemic agency in the international Knowledge Building research community and conclude by discussing challenges and opportunities to advance this line of work.

\section{EDUCATION FOR INNOVATION}

Whilst my approaches to teaching and conveying information were, at times, certainly creative, the actual activities designed for the children, and the mode in which they were instructed to approach them, tended to be linear and prescriptive ... None of the children saw imagination or creativity as ... a significant aspect of learning. -A teacher (Claxton, Edwards, \& ScaleConstantinou, 2006, p. 60)

Current designs of learning analytics are mostly rooted in the dominant practices of education and assessment established on the basis of predefined learning objectives that focus on student acquisition of well-established knowledge and skills (Schwartz \& Arena, 2013). The objectives are addressed in teaching through pre-sequenced learning contents and activities and pre-set performance measures to keep students on track and hold teachers accountable. A foundation underpinning this dominant approach to education and assessment is Bloom's (1956) Taxonomy, which classifies cognitive objectives into six levels that include, from low to high, Knowledge, Comprehension, Application, Analysis, Synthesis, and Evaluation. It has played a crucial role in expanding educational objectives beyond itemized subject-matter knowledge to include "intellectual abilities and skills" represented by the higher levels of the taxonomy (Krathwohl, 2002). Since it was first developed as an assessment framework, the

\footnotetext{
${ }^{1}$ We treat "learning analytics" as singular when it refers to the scholarly field or the systematic approach of mining insights from learning data and plural when it means specific analytical tools or applications.
} 
(2016). Analytics for knowledge creation: Towards epistemic agency and design-mode thinking. Journal of Learning Analytics, 3(2), 139-163. http://dx.doi.org/10.18608/jla.2016.32.7

taxonomy has been applied broadly in the development of curriculum standards, lesson plans, and assessment tools.

Despite its profound influence on educators, however, Bloom's Taxonomy is less compatible with emergent cultures of learning (Thomas \& Brown, 2011), as well as real-world knowledge practices deemed important for education more recently (Bereiter, 2002). One caveat of the taxonomy is that it treats knowledge as a static entity, or in Bloom's words, as "something filed or stored in the mind" (Bloom, 1956, p. 29). It places Knowledge under cognitive skills (i.e., Comprehension, Application, etc.) an improper treatment a revised taxonomy tried to fix by establishing an independent Knowledge dimension to go along with the Cognitive Process dimension (Krathwohl, 2002). Unfortunately, in neither version of the taxonomy does knowledge even come close to being treated as "a means of production" - a more essential role that fits knowledge-based economies, where knowledge becomes objectified in human creations and further cognitive work would add value to it (Bereiter \& Scardamalia, 1998).

To develop new models of education that support innovation, we need to approach knowledge practices in line with the ways in which real-world knowledge-creating organizations operate, where knowledge is treated as shared conceptual artifacts or objects continually improved by members (Bereiter, 2002). Knowledge goals and processes cannot be pre-scripted by the central leader(s) but continually deepen and evolve through members' interactive input. As research shows, members of productive teams engage in distributed reasoning in which they perform cognitive operations (e.g., induction, deduction) and pass the results on to peers, who then use the results as the input for further cognitive operations to create new scientific theories and experiments (Dunbar, 1995). A series of small operations may lead to major, often unexpected advances. Therefore, education in line with real-world knowledge processes should treat learning as a matter of collaboratively developing shared knowledge objects and artifacts through sustained inquiry and interactions, a practice absent in typical learning experiences in schools emphasizing efficient coverage of static-state knowledge and skills.

Education for innovation and knowledge creation demands new conceptions of and designs for learning to support students taking on high-level responsibilities in their knowledge work. A frontrunner in this direction is Knowledge Building (KB) pedagogy, which aims to refashion education in line with real-world knowledge-creating processes (Scardamalia \& Bereiter, 2003). In a nutshell, KB emphasizes having students assume collective responsibility for sustained, creative work with ideas (Scardamalia, 2002). It is essentially knowledge creation in which students participate from the youngest grades, with learning as a by-product (Scardamalia \& Bereiter, 2003). As in knowledge-creating organizations, KB classrooms put ideas, knowledge objects, or conceptual artifacts, in the centre, with all types of resources (including students, teachers, technology, authoritative sources) contributing synergistically towards the advancement of ideas. By working as a collective to advance their ideas, students take on high-level cognitive responsibilities including setting goals, planning inquiry, monitoring progress, seeking and using authoritative sources, and diagnosing problems. Pedagogical designs by KB teachers scaffold student collective responsibility by nurturing a safe sociocultural environment for discourse, reminding students of each other's contributions, helping to locate external sources, and so forth. Technology, 
(2016). Analytics for knowledge creation: Towards epistemic agency and design-mode thinking. Journal of Learning Analytics, 3(2), $139-163$. http://dx.doi.org/10.18608/jla.2016.32.7

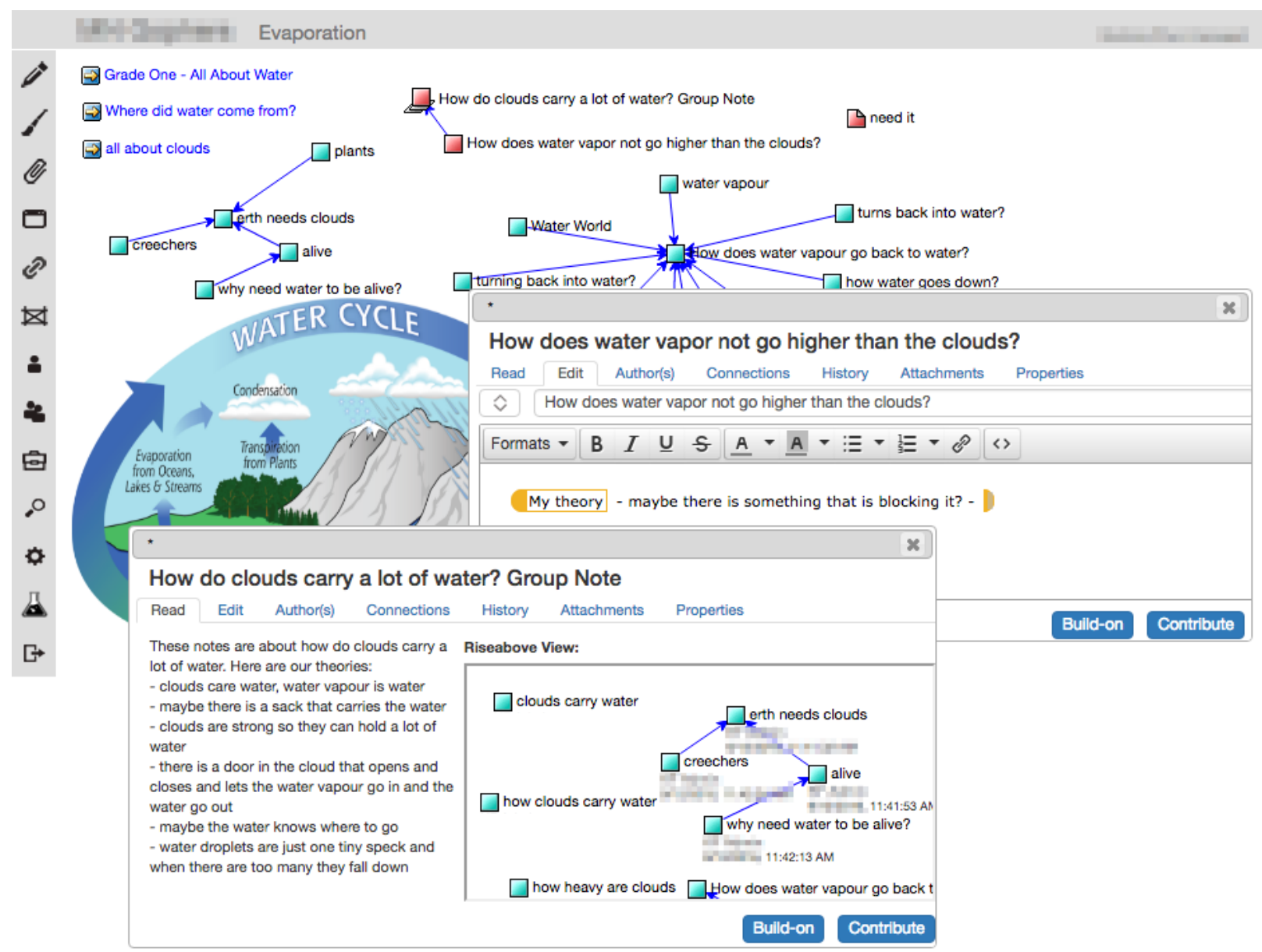

Figure 1: Main interface of Knowledge Forum (Version 6). Centre-right - one KF note, in which an idea about "how high does water vapour go" is presented. In a note, the basic unit of contribution in

$\mathrm{KF}$, users can specify the problem they want to address, use scaffolds to frame ideas, and add keywords to convey the essence of the note. Notes can be further linked in different ways, in KF terms of building on and referencing. Background - a KF view, a problem space created and designed by a

KB community to organize ideas presented in notes conceptually. A view is a two-dimensional organizing background for notes. In a view, users have the freedom to place notes in any location. They can also add graphic structures, such as a concept map, a diagram, or a scene, to help organize

notes in meaningful ways. With views and notes, KF provides an open, communal space for a community to engage in idea development. Bottom-left (front) - a rise-above note that presents a high-level summary of student ideas about "how clouds carry water." The packaged ideas can be accessed by clicking on the icon in the rise-above view.

represented by a widely used environment named Knowledge Forum (Scardamalia \& Bereiter, 2003), plays a significant role in archiving student ideas and sustaining community discourse beyond face-toface classroom sessions. It is designed with functionalities to support various operations on ideas or knowledge objects. Briefly, it enables students to contribute ideas, in the form of notes, to a communal space organized into views; it provides epistemic scaffolds (e.g., "My theory," "I wonder") in notes to help students frame their contributions; it supports sophisticated knowledge processes such as synthesizing and abstracting for deeper principles through rise-above notes (which package multiple 
(2016). Analytics for knowledge creation: Towards epistemic agency and design-mode thinking. Journal of Learning Analytics, 3(2), 139-163. http://dx.doi.org/10.18608/jla.2016.32.7

ideas together), and flexible movement of ideas across the knowledge space (through note-copying, text-referencing, idea-exporting, etc.; see Figure 1). A recent review of the literature demonstrates the broad application of KB across grade levels (from kindergarten to tertiary), subject areas (e.g., science, mathematics, engineering, medical science), and cultural settings, with its distinctions from other constructivist approaches also explained (Chen \& Hong, 2016).

To summarize, KB does not treat innovation and knowledge creation as new "ingredients" of schooling, which is an approach embraced by many $21^{\text {st }}$ century skills initiatives. Rather, it puts forward an alternative education paradigm that directly places creation and innovation at its centre. Analytics designed for such an approach need to respond to new assessment needs emerging in this context. Below, we discuss two core aspects of KB as the design focus of analytics: design-mode thinking and high-level epistemic agency.

\subsection{Design-Mode Thinking for Continual Idea Improvement}

Authentic knowledge creation requires students to take on high-level responsibility and epistemic agency for continual idea improvement. Underpinning KB practices is a specific mode of thinking, which is now coming to be called design-mode thinking (Bereiter \& Scardamalia, 2003). Design-mode thinking takes the kind of thinking professional knowledge builders (e.g., designers and researchers) do and extends it to other contexts. Specifically, knowledge builders engage in design-mode thinking when working with ill-defined or "wicked" problems (Rittel \& Webber, 1973), which are open to different definitions and to tentative solution paths of unknown destinies. As work proceeds, the nature of the problem changes, so predetermined pathways will not suffice. Progress depends on pursuing promising ideas and redirecting work based on reflection on advances and failures. The pursuit of promising directions calls for a "design mode" of thinking, which is concerned with "the usefulness, adequacy, improvability, and developmental potential of ideas" (Bereiter \& Scardamalia, 2003). In the design mode, sustained experimentation, refinement, and incremental build-on of ideas give rise to major, often unexpected advances. This design mode, in which knowledge creation operates, differs from school practices that function in a "belief mode" (i.e., focusing on acquiring "correct" answers or authoritative knowledge). For schools attuned to the knowledge age, a design-mode mindset should be all-pervasive in disciplinary courses (Bereiter \& Scardamalia, 2003). This is not to pit two modes of thinking against each other, but to highlight the need to provide students with opportunities to venture into the design mode, which is essential for knowledge creation but largely missing in education.

Studies of KB classrooms demonstrated the possibility and advantages of engaging students in increasingly deepening work with ideas reflecting design-mode thinking (Hakkarainen, 2003; Zhang, Scardamalia, Lamon, Messina, \& Reeve, 2007). Students make productive choices and go beyond what they already know to search for deeper and more sophisticated explanations. They choose fruitful, "juicy," self-generated questions (e.g., how does light travel?); build on promising ideas conducive to productive directions (e.g., light bends because its speed changes); go beyond facts to search for deeper explanations (e.g., why are colours in rainbows always in the same order?); rise above diverse perspectives for more sophisticated conceptualizations (e.g., light as both rays and waves); find 
(2016). Analytics for knowledge creation: Towards epistemic agency and design-mode thinking. Journal of Learning Analytics, 3(2), 139-163. http://dx.doi.org/10.18608/jla.2016.32.7

connections between different areas of work to develop opportunistic collaboration (e.g., connecting inquiry about vision and lenses to understand nearsightedness); and so forth (Zhang et al., 2007; Zhang, Scardamalia, Reeve, \& Messina, 2009). Design-mode thinking is central to their pursuit of increasingly deeper knowledge, an effort akin to real-world knowledge creation and dissimilar to covering itemized learning objectives informed by Bloom's Taxonomy (Bereiter \& Scardamalia, 1998).

\subsection{Epistemic Agency}

Design-mode thinking aiming at knowledge creation places stronger emphasis on epistemic agency. "Epistemic agents should think of themselves as, and act as, legislating members of a realm of epistemic ends: they make the rules, devise the methods, and set the standards that bind them" (Elgin, 2013, p. 135). Even though epistemic agency plays a role even in the most passive forms of learning, high-level epistemic agency inspires proactive engagement in one's learning processes. Successful learners take charge of their own learning, demonstrating a high degree of self-regulation, self-awareness, selfdetermination, and self-direction (Hacker, Dunlosky, \& Graesser, 2009). In KB, design-mode thinking for continual idea improvement requires an even higher level of epistemic agency that goes beyond selfregulation in accomplishing teacher-given tasks (Scardamalia \& Bereiter, 1991). In order to produce knowledge of consequences, students in KB classrooms make high-level decisions and choices normally left to the teacher: setting knowledge goals and deciding what they need to learn, choosing important problems to work on, engaging in long-term planning, assessing progress, analyzing idea connections, monitoring challenges, and choosing promising directions among multiple alternatives (Scardamalia, 2002). Such high-level agency is essential to the development of adaptive expertise beyond routine skills: Adaptive experts find ill-defined, complex problems and make continual efforts to solve them progressively, during which deeper problems are formulated, leading to more advances (Bereiter \& Scardamalia, 1993; Hatano \& Inagaki, 1986).

Innovation requires not only high-level epistemic agency, but also collective agency (Bandura, 2000) and collective cognitive responsibility (Scardamalia, 2002). Collective agency is critical when a group works together to attain a common goal: "A group's attainments are the product not only of shared knowledge and skills of its different members, but also of the interactive, coordinative, and synergistic dynamics of their transactions" (Bandura, 2000, p. 75). Aspects of collective agency, such as group efficacy, collective goal setting, and collaborative innovation (Gloor, 2005), are essentially emergent group-level properties that cannot be adequately addressed with measures derived from individuals. Yet they are fundamentally important for team-based innovation, which is usually mandatory given today's complex problems (e.g., climate change, global health issues). Recognizing collective agency is also critical for engendering collaborative learning, which happens at all agentic granularities including individuals, small groups, and communities (Stahl, 2013; Suthers \& Verbert, 2013; Zhang et al., 2009). Working as a collaborative community, members not only contribute conceptual ideas, but also offer high-level metacognitive input to collective choice-making about what problems the community should work on, what types of contributions need to be made, by and with whom, and following what timeline.

The importance of collective, epistemic agency for innovation casts doubt on dominant praxis within 
(2016). Analytics for knowledge creation: Towards epistemic agency and design-mode thinking. Journal of Learning Analytics, 3(2), 139-163. http://dx.doi.org/10.18608/jla.2016.32.7

learning analytics. In a traditional learning analytic scenario, the learners reside at the bottom of a hierarchy, being treated as "data objects" to be interpreted by "data clients" performed by teachers, institutions, and governmental agencies (Greller \& Drachsler, 2012). For example, institutional data are fed into algorithms to predict student success, with resulting predictions delivered to the teacher on demand to trigger intervention (Arnold \& Pistilli, 2012); analytics are also developed to support teacher decision-making, for instance, in orchestration of co-operative programming tasks (Berland, Davis, \& Smith, 2015). Using learning analytics to orchestrate learning (e.g., Dietz-Uhler \& Hurn, 2013; RuipérezValiente, Muñoz-Merino, Leony, \& Delgado Kloos, 2014), while being practically compatible with contemporary views of learning as social participation (Sfard, 1998), takes important knowledgecreation competencies away from students. The learning analytics community is becoming aware of this tension, arguing for treating both students and the institution as agents, who both enjoy situated, relative freedom to pursue successful learning (Subotzky \& Prinsloo, 2011). Researchers caution the danger of treating learning analytics as a part of the broader bureaucratization of student learning and advocate for a "third-space" where students and the institution engage in negotiations about assumptions, beliefs, and identities (Prinsloo, Slade, \& Galpin, 2012). Hence, student agency needs to be stressed in applications of learning analytics (Wise, 2014), as does their epistemic agency in knowledge processes.

\section{ANALYTICS FOR KNOWLEDGE BUILDING}

Learning analytics for KB needs to capture and provide feedback on the design-mode thinking of students, who act as epistemic agents to continually improve ideas. In the following sections, we develop two guiding principles for KB analytics, and then elaborate these principles through example tools and research projects. Specifically, we argue that analytics for KB needs to be 1) agency-driven and choice-based; and 2) progress-oriented, integrative of multi-level, multi-unit, and multi-timescale data produced in progressive KB discourse. Figure 2 presents a model of KB analytics highlighting two higher order competencies discussed in the previous section, together with the design principles to be elaborated below.
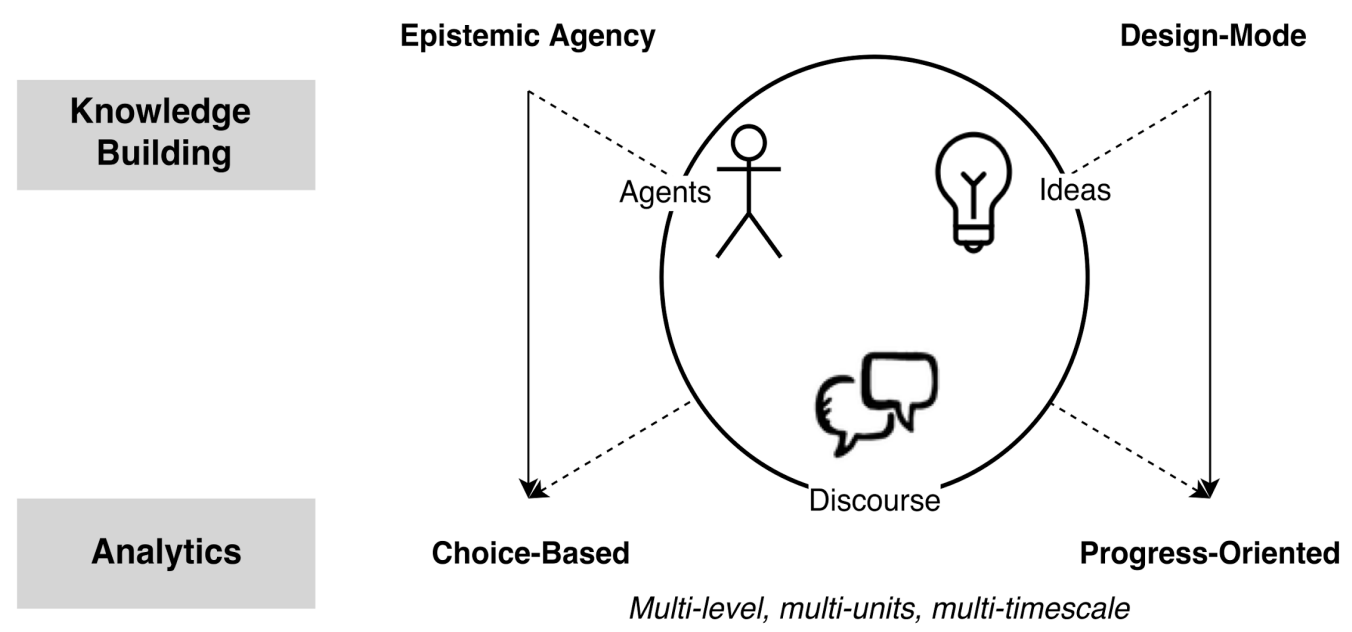

Figure 2: A conceptual model of knowledge-building analytics. 
(2016). Analytics for knowledge creation: Towards epistemic agency and design-mode thinking. Journal of Learning Analytics, 3(2), 139-163. http://dx.doi.org/10.18608/jla.2016.32.7

\subsection{Agency-Driven, Choice-Based Analytics}

Current learning analytics primarily focus on the development of knowledge and skills as a result of completing predefined tasks and activities. Despite the importance of such work, "assessments organized around knowledge are too far removed from the realm of action and the future learner adaptations that education cares about" (Schwartz \& Arena, 2013, p. 67).

The importance of epistemic agency and design-mode thinking in KB leads us to recognize choices as a fresh angle to both understand and scaffold higher order competencies. Epistemic agency essentially means the capacity to make choices when advancing one's understanding. Epistemic agents "form, sustain, and revise their beliefs, methods, and standards" as they deem necessary, with epistemic autonomy to make choices regardless of circumstances (Elgin, 2013, p. 139). Choice-making in a collective, or in an epistemic community (Haas, 1992), further calls for consideration of an individual's personal appetites (and aversions) in relation to those of others for the sake of joint and interdependent interests. Choice-making thus becomes essential for a team's endeavours of solving wicked problems, during which the team members face multiple tentative solution paths and are collectively responsible for the consequences of their choices. Therefore, learning environments that encourage epistemic agency and design-mode thinking should provide learners with abundant epistemic choices.

Attending to choices that reflect epistemic agency and design-mode thinking provides a fresh angle for devising learning analytics for high-level competencies. Choice-based assessment is a nascent idea (Schwartz \& Arena, 2013). As rich forms of learning interactions and transactions are supported by digital environments, analyzing choices made in digital transactions provides new opportunities for understanding learning. As Schwartz and Arena (2013) argue, choice, rather than static-state knowledge, provides a stronger interpretative framework for learning outcomes - knowledge is an enabler, but choice captures much more, because making good choices does not depend solely on knowledge but also on a variety of intrapersonal, interpersonal, and environmental factors. In a similar vein, a new culture of learning calls for a transition from "knowledge stocks" - i.e., canons to be protected and transferred - to "knowledge flows" that are fluid and constantly changing with less attachment to institutional warrants (Thomas \& Brown, 2011). Making choices in knowledge processes is a strong indicator of epistemic agency, as is the capability to decide among multiple choices in knowledge "flows." Compared to measuring knowledge "stocks" and cognitive skills, which are emphasized by Bloom's dominant Taxonomy, assessing choice-making in action is better aligned with the essence of competencies for knowledge creation and innovation. Analyzing learner choices as driven by epistemic agency would capture much more dynamic, adaptive, and complex aspects of learning in the digital age.

If choices become the most critical "input" for learning analytics, the "output" of choice-based analytics should aim towards empowering reflexive choice-making by learners or knowledge builders. In scenarios where analytics are aligned with dominant frameworks of learning measurement, the non-student users of analytics usually make centralized decisions on learning, for good reasons in many cases. However, one significant challenge facing choice-based analytics for higher order competencies is to maintain the 
(2016). Analytics for knowledge creation: Towards epistemic agency and design-mode thinking. Journal of Learning Analytics, 3(2), 139-163. http://dx.doi.org/10.18608/jla.2016.32.7

balance between priming for better choices and scaffolding epistemic agency. While the establishment of reliable assessment of choice-making is critical, choice-based analytics could start from raising awareness of choices among learners and engaging them in reflecting upon their own choices in relation to those of others. In KB, defined as a collective process of advancing community knowledge through communal discourse (Scardamalia \& Bereiter, 2003), choices driven by students' epistemic agency abound. Important choice-making reflecting high-level epistemic agency and design-mode thinking happens at least in the following three aspects, based on current literature:

1. Choice-making among emergent ideas. The central business of KB is idea improvement, which is preconditioned by idea diversity, just as biodiversity is critical for ecosystems (Scardamalia, 2002). One important aspect of epistemic agency in KB, hence, is to make choices among diverse, and sometimes competing ideas, and determine the most promising ones for a community to collectively labour on (Chen, Scardamalia, \& Bereiter, 2015).

2. Choice-making around emergent themes or higher-order conceptual structures. An idea never stands alone but is always surrounded by others. As KB progresses through community discourse, complex structures of ideas constantly emerge. They could be themes of inquiry that address distinctive principal problems (Zhang et al., 2007), or "rise-above" ideas that synthesize interconnected ideas (Scardamalia \& Bereiter, 2014). To continually advance the community's knowledge, one important issue for students is to collectively grapple with these high-level, emergent knowledge structures. Collective choice-making around these structures, such as choosing which lines of inquiry to follow and deciding means to advance them, is critical for deepening knowledge building.

3. Choice-making of discourse moves. KB as a community enterprise treats every community member as a legitimate contributor. As epistemic agents, students contribute to KB discourse in a variety of ways, including posing questions, theorizing, introducing new information, making synthesis, monitoring discussion, and so forth (Chuy et al., 2011), all of which are valued in a KB community. Choices made among these different "epistemic moves" figure at both single contributions and high-level knowledge structures (e.g., threads, views; see Figure 1). When making a contribution, decisions are made on which epistemic moves could help to address a particular knowledge problem; to advance a "thread" of inquiry, students need to analyze which epistemic moves are needed overall (Resendes, Scardamalia, Bereiter, Chen, \& Halewood, 2015).

Choice-based KB analytics may begin with these key aspects of choice-making pertinent to collective knowledge advancement and gradually expand to other areas.

\subsection{Progress-Oriented Analytics}

While choices are important indicators of key competencies in KB, the productivity of such choices 
(2016). Analytics for knowledge creation: Towards epistemic agency and design-mode thinking. Journal of Learning Analytics, 3(2), 139-163. http://dx.doi.org/10.18608/jla.2016.32.7

needs to be further benchmarked by achieved knowledge progress over time, including progress of individual understanding as well as collective knowledge of a community. Given KB's focus on sustained idea development, KB analytics is naturally oriented to the progress of understanding emerging from interactive idea inputs from community members. Such a focus on the progress of understanding is common among extent learning analytics. For example, Khan Academy provides analytics of learning activities to assess and demonstrate learning progress (Ruipérez-Valiente et al., 2014); intelligent tutoring systems also model understanding based on one's interactions with the tutor (Allen, Snow, \& McNamara, 2015; Desmarais \& Baker, 2012). Existing work in this area will inform the implementation of analytics to assess knowledge progress in KB.

The KB literature has suggested three important aspects of idea progress: conceptual depth, breadth, and the emergence of new strands of inquiry. The first two aspects, i.e., the depth and breadth of community knowledge, are achieved through idea (co-)elaboration and diversification in knowledgebuilding communities (Hong \& Sullivan, 2009). Distinctive from most current progress-oriented analytics focusing on individuals, KB analytics needs to attend to both the individual and community levels. At the individual level, known proxies of knowledge progress include content and lexical measures (Chen, Ma, Matsuzawa, \& Scardamalia, 2015) and semantic overlaps with curriculum standards (Teplovs \& Fujita, 2009). At the community level, researchers have experimented with techniques such as term clouds (Hong \& Scardamalia, 2014) and topic modelling (Chen, 2014; Sun, Zhang, Jin, \& Lyu, 2014) to assess community knowledge. Latent Semantic Analysis has been successfully applied to analyze text coherence (Foltz, Kintsch, \& Landauer, 1998) and could be applied to assess idea coherence in KB. Additional behavioural measures extracted from activity logs could be used to augment the analysis of content coherence with insights into students' social interactions (e.g., Segedy, Kinnebrew, \& Biswas, 2015) to address basic but important questions such as "whether students incorporated ideas they read into those they wrote." New development is needed to better assess both dimensions of knowledge progression at multiple levels in KB.

As for the third aspect, KB analytics needs to attend to emergent directions and strands of inquiry. In particular, assessment in KB is transformative, feeding forwards to potential progresses attainable from the current state of community knowledge. This is different from, for instance, analytics that recommend potentially helpful information, or hints given by intelligent tutors based on assessment of student knowledge. In contrast, since KB is a closer parallel to "swarm creativity," where emergent interactions lead to collective advances (Gloor, 2005), KB analytics needs to feed forwards to selforganization around emergent directions in a community (Bereiter \& Scardamalia, 2013). This characteristic needs to be considered without losing sight of the epistemic agency principle, so that analytics do not take away agency, but rather enable reflective noticing and adaptive structuring, scaffold clearer communication, and assist "hunting" for promising uncertainties in the community. For example, Idea Thread Mapper (to be elaborated below) enables students' reflective noticing and structuring of emergent strands of inquiry (Chen, Zhang, \& Lee, 2013; Zhang et al., 2015). More work is needed to strengthen this aspect of analytics. 
(2016). Analytics for knowledge creation: Towards epistemic agency and design-mode thinking. Journal of Learning Analytics, 3(2), 139-163. http://dx.doi.org/10.18608/jla.2016.32.7

To summarize, KB analytics, as it emphasizes agency, choice, and progress, embraces the transformative power of analytics, favouring a view treating "analytics as learning," in contrast to popular emphasis on analytics about, of, or for learning. Instead of treating learning analytics as a set of tools for evaluating learning and learners, analytics has the power to carry on cognitive actions to support KB processes, with cognition being distributed among community members, knowledge artefacts, and analytics. Such a view of analytics, albeit difficult to achieve, demands integral views of different units of social interactions at different time scales in KB. Semantic, temporal, social, and network analyses need to be integrated to identify distributed knowledge, idea progress, and "rotating leadership" in KB communities (e.g., Ma, Matsuzawa, Chen, \& Scardamalia, 2016).

\section{EXAMPLES OF KNOWLEDGE BUILDING ANALYTICS}

One of the earliest analytics developed for Knowledge Forum, the most broadly used KB environment, was the Analytic Toolkit (ATK; Burtis, 1998). The toolkit provides comprehensive summary statistics on activities in a Knowledge Forum database at both the individual and community levels. An evolving suite of lightweight analytic applets are also available for learners to monitor the behavioural, lexical, semantic, and social aspects of discourse patterns (e.g., Teplovs, Donoahue, Scardamalia, \& Philip, 2007). External analytic tools with unique design goals and features, such as Knowledge Connection Analyzer (van Aalst, Mu, \& Yang, 2016) and Knowledge Building Discourse Explorer (Oshima, Oshima, \& Matsuzawa, 2012), have also been actively developed.

To elaborate on the design principles introduced earlier, below we present recent research projects that use analytics to support students' epistemic agency and design-mode thinking in KB. For each project, we highlight the analytics tools oriented toward students' agency-driven choices and related idea progress, and synthesize the educational use of the analytics tools and their impact on KB. The main goal is not to present best practices, but to illuminate possibilities and to encourage further improvements.

\subsection{Promising Ideas Tool: Choice-Making among Emergent Ideas}

Idea improvement is the central concern of KB. While a pool of diverse ideas contributed by students provides the foundation for possible improvement, a key concern related to design-mode thinking and epistemic agency is the determination of which ideas produced by the community are promising and worth further efforts. The practice of judging the potentials of ideas is evident in creative processes of all kinds, when principled knowledge is scant and many competing ideas emerge at the same time (Bereiter, 2009). Such judgments have been explored in studies of creativity (Gardner, 1994; Wertheimer \& Wertheimer, 1959) and creative expertise (Bereiter \& Scardamalia, 1993). Choices made among ideas in these circumstances - propelled by epistemic agency and design-mode thinking eliminate or delay other alternatives and greatly influence the trajectory of idea development.

To devise analytics for choice-making among emergent ideas, implementation efforts were made to first capture the students' deliberate choices. An embedded facility for identifying promising ideas in Knowledge Forum was developed, with a goal to make the choice of promising ideas a routine in KB for 
(2016). Analytics for knowledge creation: Towards epistemic agency and design-mode thinking. Journal of Learning Analytics, 3(2), $139-163$. http://dx.doi.org/10.18608/jla.2016.32.7

students as young as 8 years old (Chen, Scardamalia, \& Bereiter, 2015). With this facility, students could highlight a text snippet within a Knowledge Forum note as a promising idea (see Figure 3.a). Contextual data around a choice - information about who (the agent/student), where (the note and view in which an idea is tagged), when (timestamp), and for what - are all captured to afford later reflection by students.

After students identify promising ideas, their choices are then harnessed by analytics to support collective deliberation oriented towards knowledge progress. Tagged ideas are aggregated, merged based on text overlaps (i.e., idea A and B are merged if A contains B), ranked based on the number of "hits," and visualized for students to process. In a network layout of the idea aggregation window (see Figure 3.b), similarities among ideas are calculated (using the character-based Damerau-Levenshtein similarity approach), and turned into an interactive visualization that enables students to explore connections among identified ideas (by clicking on the edges). In this layout, an edge between two ideas denotes a similarity between them that surpasses a given threshold, and is intended to encourage students to explore their relations. By clicking on the edge between two linked ideas, students could further inspect their connections, which could lead to syntheses and "rise-above" ideas. Cognition becomes distributed between analytics and students, but students' epistemic agency remains at the centre, as students take advantage of analytics to sift through identified promising ideas, choose the most promising ones, and export them to a new workspace for further inquiry (see Chen, Scardamalia, \& Bereiter, 2015).

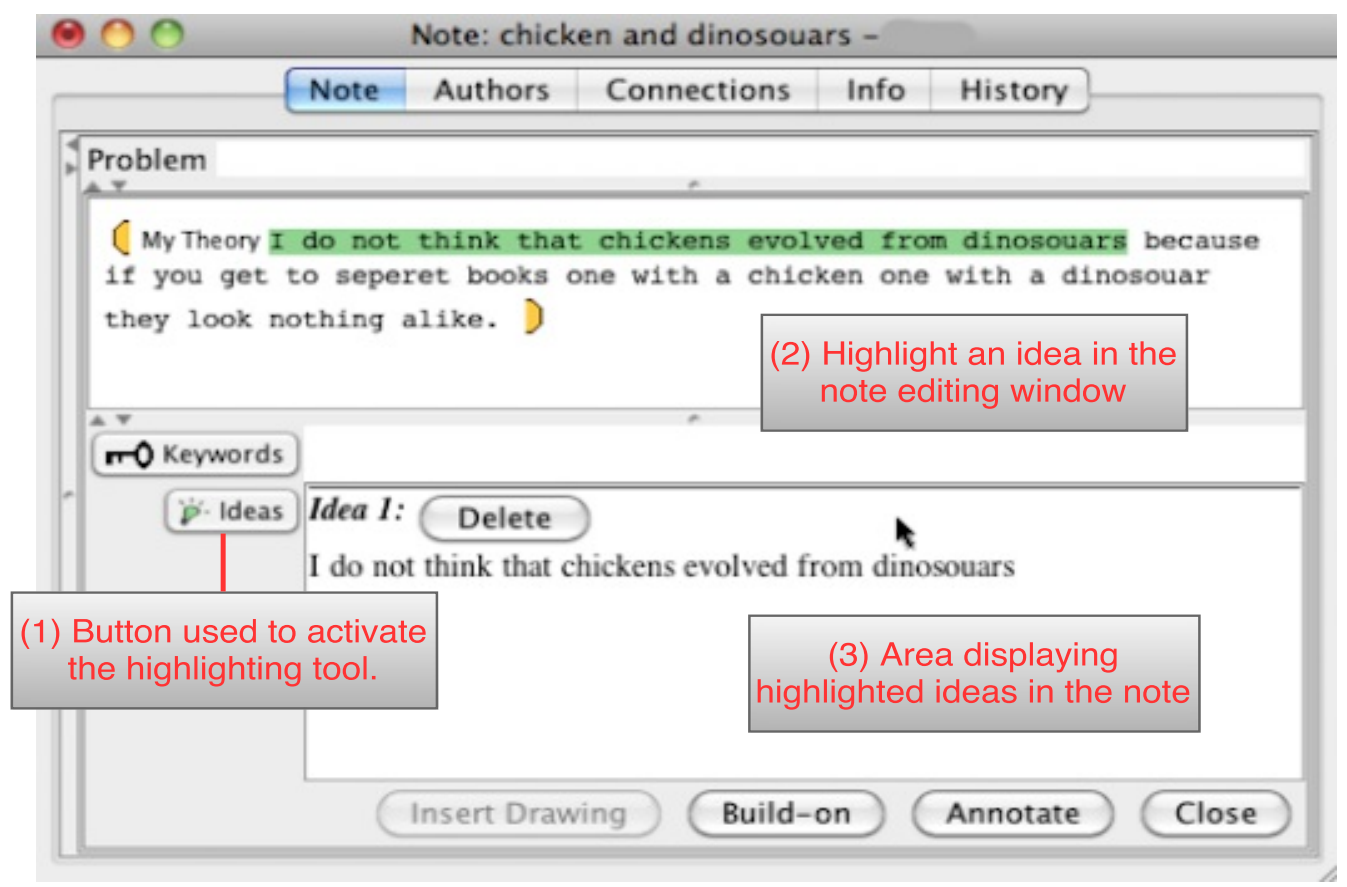

(a) A note with one promising idea highlighted from a third grade class.

Figure 3: The Promising Ideas Tool. 
(2016). Analytics for knowledge creation: Towards epistemic agency and design-mode thinking. Journal of Learning Analytics, 3(2), 139-163. http://dx.doi.org/10.18608/jla.2016.32.7

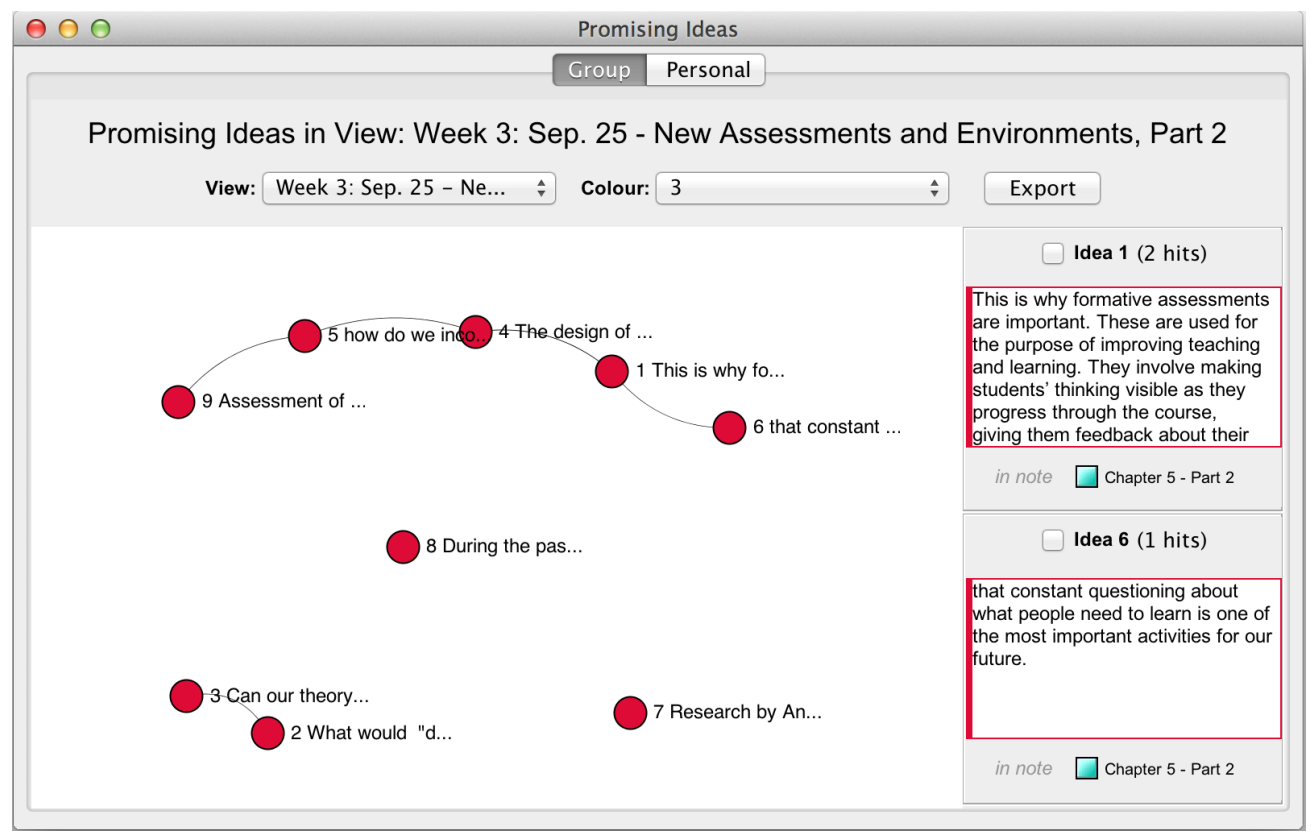

(b) The network layout of idea aggregation window from a graduate-level class. In this layout, semantic linkages among ideas are visualized. The user can review two ideas together by clicking on the edge between them.

Figure 3: The Promising Ideas Tool.

To date, no efforts have been made to assess the quality of student choices of promising ideas. The focus thus far has been on ensuring that students' epistemic agency is not undermined but empowered by analytics, which scaffold student attempts to improve their ideas. As demonstrated earlier, rather than trying to optimize choices based on trained optimal models, KB researchers applied simple textmining algorithms and visualization techniques to build tools to uncover the high-order competency of identifying promising ideas among young learners. In two empirical studies conducted in third- and sixgrade classes (eight-to-twelve-year old students), the Promising Ideas tool, coupled with designed pedagogical supports, has shown promise in improving student awareness of community ideas, promoting collaboration (reflected by social network analysis), facilitating community knowledge (demonstrated through content analysis and group comparisons), and advancing students' epistemic beliefs (measured by established instruments; Chen, 2016; Chen, Scardamalia, \& Bereiter, 2015).

\subsection{Epistemic Discourse Moves Tool: Choosing Moves to Drive Discourse Forward}

In science, where KB has been broadly applied (Chen \& Hong, 2016), epistemic moves to achieve deeper understanding include seeking plausible causal models, problematizing models, detecting flawed evidence, and building from counter-evidence (Perkins \& Grotzer, 2000, p. 7). For KB in general, epistemic moves to build explanatory theories (Bereiter, 2002) include posing thought-provoking questions, theorizing, introducing new information, working with information, synthesizing and comparing, and supporting discussion (Chuy et al., 2011). An important task to support high-level epistemic agency, thus, is to expand the student repertoire of epistemic moves to promote their design- 
(2016). Analytics for knowledge creation: Towards epistemic agency and design-mode thinking. Journal of Learning Analytics, 3(2), $139-163$. http://dx.doi.org/10.18608/jla.2016.32.7

mode thinking around ideas. One option for devising analytics to support this area is to capture student choices of different moves, and then engage students in reflecting on previous moves and choosing the next fruitful moves. These high-level knowledge processes are described as meta-discourse - the philosophical sense of "discourse about discourse" (Resendes et al., 2015) - which aims to advance KB and in the meantime contribute to improving students' epistemic fluency (Morrison \& Collins, 1996) in explanation building.

To support meta-discourse by students, an Epistemic Discourse Moves tool has been developed for Knowledge Forum (Figure 4). The tool garners epistemic markers, known as scaffolds (e.g., "My theory...," "I need to understand...," "A better theory...") that are left by students when making contributions (see Figure 1). By aggregating scaffold use, the tool captures epistemic moves made by students and feeds this information back to them. As illustrated in Figure 4, the tool presents the counts of different scaffolds used by the community as a bar graph. New scaffold uses that appear after the tool is activated are shown in red. By clicking on a scaffold, students can also interactively filter notes in a Knowledge Forum view. Such functionalities are designed to help raise student awareness of their choices/actions, and to navigate the complex idea landscape in their KB work, with a goal to inform choice-making involving epistemic moves.

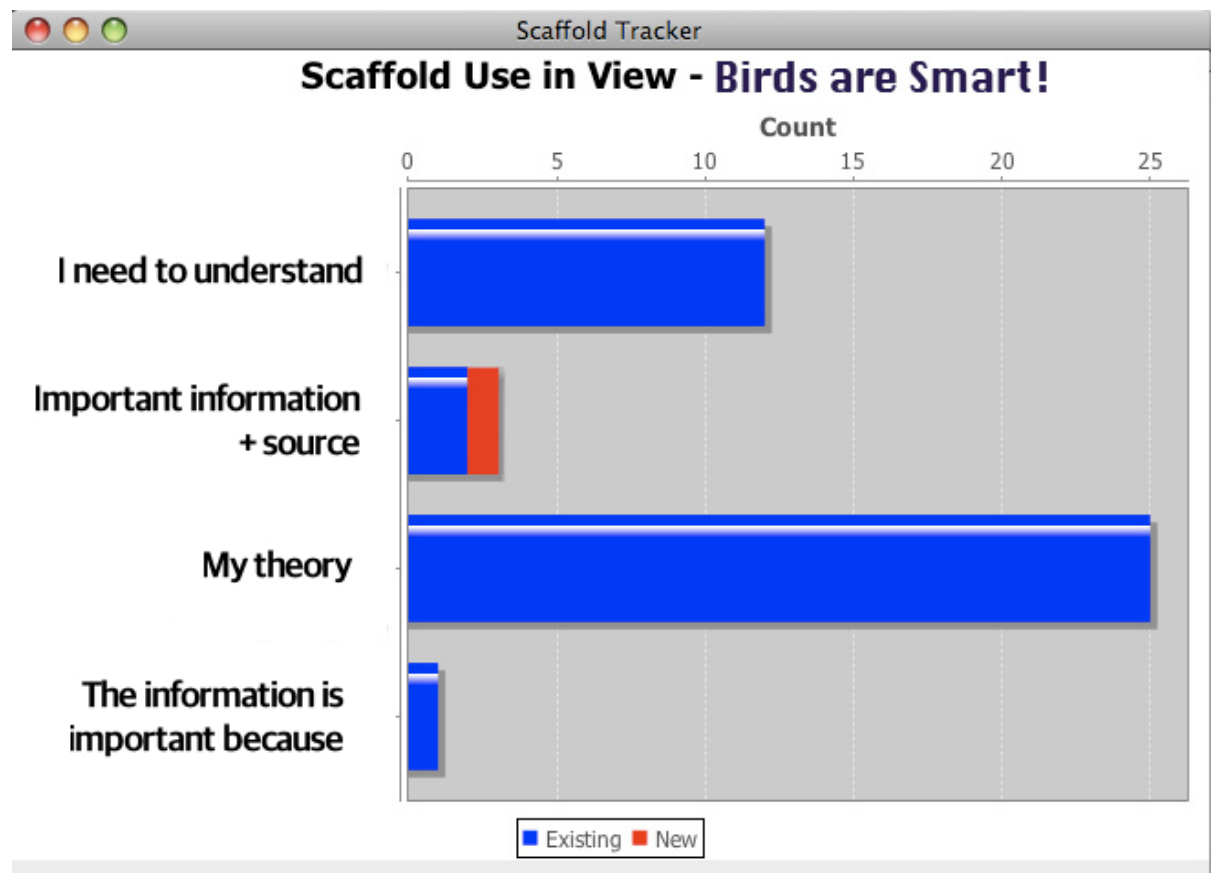

Figure 4: Epistemic Discourse Moves tool in a second grade view about birds.

Simple as the tool appears to be, when it was piloted in a second-grade class (seven-to-eight-year-old children), students immediately realized they had contributed too many theories and questions but not enough information (Resendes et al., 2015). Visualizations created forms of feedback that allowed second-grade students to attend to facets of their knowledge work that are otherwise inaccessible and indigestible to them. With pedagogical interventions designed around this analytics tool, students were 
(2016). Analytics for knowledge creation: Towards epistemic agency and design-mode thinking. Journal of Learning Analytics, 3(2), 139-163. http://dx.doi.org/10.18608/jla.2016.32.7

able to incorporate into their discourse moves that are sophisticated for their age (Resendes et al., 2015). Their choices of moves - both initial ones when contributing an idea and later ones after epistemic gaps are recognized - are clear indicators of epistemic agency and design-thinking efforts to achieve knowledge progress. The tool does not prescribe actions for students. Instead, it initiates group dialogues, with students maintaining the epistemic agency to choose the next moves.

\subsection{Idea Thread Mapper: Grappling with Emergent Knowledge Structures}

Besides analytics to trace choices around discourse moves, further support is needed to capture choices made by students around higher order, collective structures of KB in their unfolding discourse. Instead of following pre-scripted tasks and procedures of inquiry, students in a KB community need to enact high-level agency for defining what needs to be investigated and how. They co-construct the collective focus and landscape of the community's research and discourse, as collective structures that frame the shared, emergent objects of inquiry, the unfolding strands of inquiry and norms of contributions, and deeper needs of knowledge to be addressed. However, in current online discussions, students' ideas are contributed in distributed online posts that extend over time; there is a lack of tools to help students monitor the collective landscape, progress, and directions emerged from their distributed, long-term discourse (cf. Hewitt, 2001; Suthers, Vatrapu, Medina, Joseph, \& Dwyer, 2008). Consequently, their online discourse may become disconnected and ill-grounded, and lack progressively deepening moves to advance understanding (Zhang et al., 2009).

To support students' reflective monitoring and adaptation of collective structures of inquiry practices, Zhang and colleagues designed a timeline-based, collective discourse-structuring tool: Idea Thread Mapper (ITM) (Chen, Zhang, \& Lee, 2013; Zhang et al., 2015). On top of micro-level representations of ideas using online postings and build-ons (physical conversation threads), ITM incorporates "idea threads" as an emergent structure in online discourse. Each idea thread, as shown in Figure 5, includes as a sequence of discourse entries (possibly involving several build-on trees - see Figure 1) that investigates a shared epistemic object (e.g., allergies), as an unfolding strand of inquiry (Zhang et al., 2007). Features of ITM signify collective knowledge structures reflected in the online KB discourse, including 1) using the thread topics and "Journey of Thinking" syntheses to highlight the shared epistemic objects being investigated and absences of knowledge to be addressed by the community; 2) using timeline-based discourse mapping to visualize the unfolding, interrelated strands of inquiry practices focusing on the epistemic objects; and 3) retrieving members' participatory roles in the different strands of inquiry. The collective landscape of a whole KB initiative is mapped out as a cluster of idea threads that investigate a set of interrelated problems through the contributions of all members. Visualization tools further show the intensity of contributions in each thread and cross-thread connections, including cross-thread build-on links and connective contributions that simultaneously address two or more objects of investigation. Automated text analyses drawing upon LightSIDE (formerly known as TagHelper - see Rosé et al., 2008) and topic modelling help students retrieve notes related to each object of inquiry and profile the notes based on various types of moves to deepen understanding (e.g., questions, explanations, facts). 
(2016). Analytics for knowledge creation: Towards epistemic agency and design-mode thinking. Journal of Learning Analytics, 3(2), $139-163$. http://dx.doi.org/10.18608/jla.2016.32.7

\section{(-) Idlea Thread Mapper}

You are working on Project: Human Body
Click "Thread" to add or view/edit threads. Click "Map" to show threads.

Range: Show Full Time Range Note: Hide Trte I Show Auther I Hide Buld-on I Show Reference I Show Hiahlighted Notes I Hide Commol

\begin{tabular}{|c|c|c|c|c|c|c|c|c|c|c|c|c|c|}
\hline & Apr 2012 & Apros & Apros & Apro7 07 & Apro9 & Apr 11 & $A Q P 13$ & Ape is & Apr 17 & Apr 19 & Apr 21 & Apr 23 & Apr 25 \\
\hline 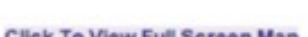 & Aor 2012 & Tue 09 & Thu cs & Sat 07 & Mon 09 & Wod 11 & Fo 13 & ADE 15 & Tue 17 & Thu 10 & Sat 21 & Non 23 & $7_{\text {wed 2t }}$ \\
\hline
\end{tabular}

\begin{tabular}{l} 
Death \\
4 note(s) by 2 author(s) \\
Allergies \\
11 note(s) by 9 author(s) \\
Memery \\
10 note(s) by 10 author(s) \\
the heart \\
2 note(s) by 3 author(s) \\
digestion \\
2 note(s) by 2 author(s) \\
inlury \\
5 note(s) by 4 author(s) \\
Brain 19 note(s) by 15 author(s) \\
\hline nerve note(s) by 13 author(s) \\
\hline \begin{tabular}{l} 
Sleep note(s) by 9 author(s) \\
\hline
\end{tabular}
\end{tabular}

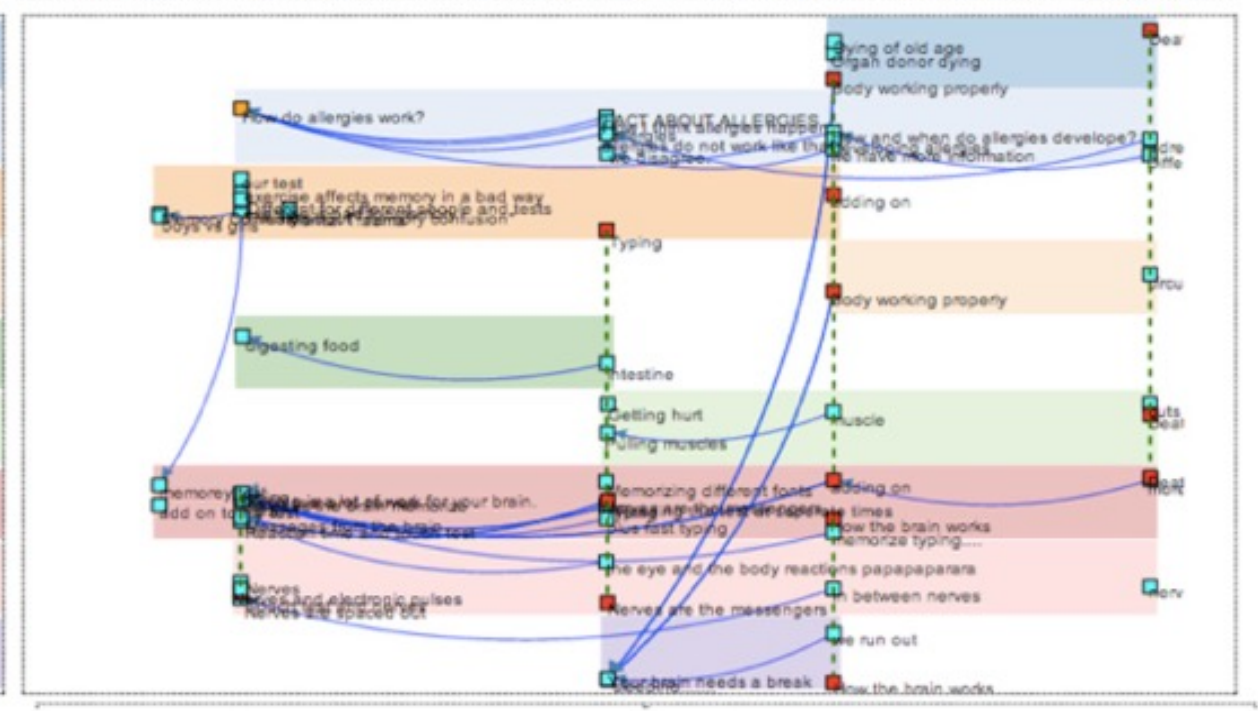

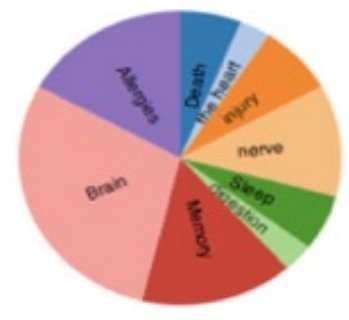

Example analyses: Distribution of notes in threads

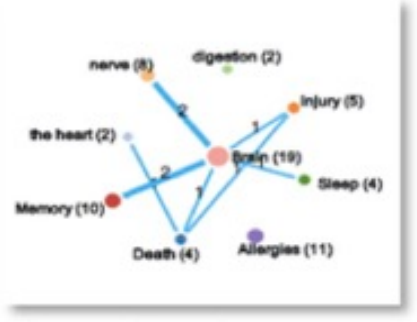

Cross-thread connection

Figure 5: A map of idea threads created by a Grade 5/6 classroom studying the human body. Each coloured stripe in the upper map represents an idea thread extending from the first until the last note contributed addressing its focal object of inquiry (e.g., allergies). Each square represents a note; a blue line between two notes represents a build-on link; a vertical dotted line marks notes that are shared between different threads discussing interrelated issues. The example analyses (bottom) show the distribution of notes in the different idea threads and conceptual connections between the threads based on cross-thread common notes. 
(2016). Analytics for knowledge creation: Towards epistemic agency and design-mode thinking. Journal of Learning Analytics, 3(2), 139-163. http://dx.doi.org/10.18608/jla.2016.32.7

ITM can be used by teachers to trace progress of student discourse in addressing important knowledge themes. More importantly, it is used by students to enact their high-level responsibility for structuring and deepening collective discourse over time to achieve sustained idea advancement. ITM-supported classroom designs engage students in reflexive monitoring of their community space and decisionmaking on next steps of community discourse, including existing knowledge objects to be deepened and new objects of inquiry to be addressed. A set of studies was conducted among third- through sixthgrade classrooms (eight-to-twelve-year-old students) equipped with Knowledge Forum and ITM (Chen et al., 2013; Zhang, Chen, Chen, \& Mico, 2013; Zhang et al., 2015). In each KB initiative that extended over multiple months focusing on one core science area, students used ITM to co-structure their online discourse around significant epistemic objects as unfolding idea threads, and, on an ongoing basis, update the threads in reflection of new progress. The analysis showed that, with proper pedagogical supports, the young students were able to construct and interpret the idea thread maps and use the information to reflect on advances and connections in the unfolding lines of inquiry, decide on deeper issues to be addressed, and plan inquiry activities to address these needs. The ITM-aided reflective monitoring and structuring of online discourse played a positive role in increasing student awareness of their community's collective foci and progress and fostering more connected discourse moves to generate deep and coherent explanations of scientific issues (Zhang et al., 2015).

As noted above, ITM and the reflective processes it enables support students' agency-driven choices to frame and direct productive lines of inquiry emerging from diverse contributions. Automated analyses in ITM further support students' sense-making and syntheses of collective idea progress at the community level. Further design and research needs to better support and understand the micro-macro interaction to capture how diverse individual contributions give rise to the community's shared foci and strands of inquiry, and how representations of the shared foci and strands of inquiry are used by individuals to guide their reflective choices about their ongoing participation and contribution.

\section{DISCUSSION AND CONCLUSION}

One central argument of this article is as follows: To consider learning analytics for higher order competencies, we need first to look beyond dominant views of educational objectives and attend to competencies critical for innovation-driven societies. Grounded in an extended body of literature, we highlight high-level epistemic agency and design-mode thinking as two pivotal components of education for knowledge creation. We then situate the discussion within the distinctive Knowledge Building pedagogy and propose that KB analytics needs to be agency-driven, choice-based, and progressoriented. To demonstrate possibilities, we present ongoing learning analytics initiatives representing these design principles. Despite varied educational contexts and research goals, the analytics projects presented show promise for facilitating these higher order competencies (i.e., epistemic agency and design-mode thinking) in empirical studies.

The second argument we made is that student agency should not be trivialized when devising learning analytics for higher order competencies. When data analytics are applied in education, special care 
(2016). Analytics for knowledge creation: Towards epistemic agency and design-mode thinking. Journal of Learning Analytics, 3(2), $139-163$. http://dx.doi.org/10.18608/jla.2016.32.7

needs to be taken regarding student agency because of the complexity of power relations among stakeholders (Slade \& Pinsloo, 2013). This is especially true if the goal of education is to help learners become autonomous human beings (Kamii, 1984) and become (or not cease to be) creators and innovators (Scardamalia \& Bereiter, 2014). This argument builds upon the caution that learning analytics should be explicit about its underlying beliefs in epistemology, assessment, and pedagogies (Knight, Buckingham Shum, \& Littleton, 2014), and also embraces a call for attention to student agency and sense-making dialogues when analytics are applied (Wise, 2014). Our emphasis on epistemic agency and choices deepens the idea of aiding and capturing student choice-making to assess learning (Schwartz \& Arena, 2013). In the examples outlined in this article, analytics describe non-evaluative information, while students evaluate the presented information and make choices oriented towards progress. The relationship between analytics and learners becomes more collaborative and dynamic, with cognition distributed on both sides. In this way, learning analytics is no longer confined within the acquisition of knowledge or skills, but becomes enlarged to cover cultivation of metacognitive facts, epistemic fluency, and habits of mind (Bereiter \& Scardamalia, 2013) - all representing higher order competencies.

Our arguments are destined to be criticized regarding issues of validity and reliability in assessment development. For instance, the use of choice as an interpretative framework of learning is still new and needs substantial work to establish validity and reliability. Nonetheless, "the methodological demand of reliability coincides with a tendency of people to take an essentialist perspective that reifies assessments into stable traits or essences of a person - individual properties that do not change" (Schwartz and Arena, 2013, p. 117). The issues of validity and reliability need to be revisited when constructing adaptive and dynamic assessment of competencies. Building analytics to assess designmode thinking is an underexplored and difficult task. One fundamental difficulty is a lack of understanding about what constitutes design-mode thinking, as the underlying constructs and what features it consistently reveals in innovative processes are understudied. An early fixation with validity and reliability can suffocate innovation in choice-based analytics. An alternative path, which may help mitigate this difficulty, is to rethink whether accurate measurement aspired by educational assessment (cf. Ellis, 2013) would be absolutely necessary for learning analytics in general. While learning analytics is predominantly tied to assessment, if the goal is to advance designs of analytics, avoiding obsession with accurate assessment would enable iterative designs in the absence of principled knowledge (Bereiter, 2009). This approach presents a transition from the popular approach of working backwards from standards when devising analytics, towards an approach emphasizing feeding forwards to the discovery of students' higher order competencies.

Learning analytics focusing on choice-making is in an early stage and faces serious challenges. In addition to validity and reliability, more work is clearly needed to conceptualize choices made in learning processes. Research of self-regulated learning deals with student choices of learning tactics (Winne, 1995; Winne \& Hadwin, 2013). However, important work is needed to extend research into choices beyond individual learning to collaborative KB and knowledge creation, as is basic research of human choices (e.g., Figner et al., 2010; Shafir, 1993). Another more practical challenge facing choice-based learning analytics is the difficulty of capturing choices made in broader contexts. A more holistic picture 
(2016). Analytics for knowledge creation: Towards epistemic agency and design-mode thinking. Journal of Learning Analytics, 3(2), $139-163$. http://dx.doi.org/10.18608/jla.2016.32.7

of choice-making in complex environments requires collection of multimodal data beyond online digital traces (e.g., Olguin, Gloor, \& Pentland, 2009).

Future work is clearly needed to address these challenges faced by analytics for KB and knowledge creation. Research programs are forming to tackle these issues in the KB research community. The adopted approach, again, is to instantiate conditions and environments for higher level competencies, instead of working backwards from education standards. This approach opens the door to exceed targeted educational outcomes and to uncover new competencies beyond the consensual expectations of stakeholders (Scardamalia, Bransford, Kozma, \& Quellmalz, 2012). Learning analytics is wellpositioned to democratize learning accomplishments by moving away from a traditional fixation with standards and tests to designing environments, analytics, and practices that nurture learners' creative moves or "knowledge flows" (Thomas \& Brown, 2011).

\section{ACKNOWLEDGEMENTS}

We acknowledge the dedicated work by colleagues in the Knowledge Building International community (http://ikit.org/kbi/) over the past three decades, and more specifically research from the Institute for Knowledge Innovation and Technology at the University of Toronto and the Technology and CoCreativity in Learning Lab of the University at Albany that has directly informed this paper. We especially thank Drs. Marlene Scardamalia and Carl Bereiter for their influence on our thinking about learning analytics and knowledge building. The contribution of the second author to this paper was enabled by a Cyberlearning grant from the National Science Foundation (IIS 1441479).

\section{REFERENCES}

Allen, L. K., Snow, E. L., \& McNamara, D. S. (2015). Are you reading my mind? Modeling students' reading comprehension skills with natural language processing techniques. Proceedings of the $5^{\text {th }}$ International Conference on Learning Analytics and Knowledge (LAK '15), 246-254. http://dx.doi.org/10.1145/2723576.2723617

Arnold, K. E., \& Pistilli, M. D. (2012). Course Signals at Purdue: Using learning analytics to increase student success. Proceedings of the $2^{\text {nd }}$ International Conference on Learning Analytics and Knowledge (LAK'12), 267-270. http://dx.doi.org/10.1145/2330601.2330666

Bandura, A. (2000). Exercise of human agency through collective efficacy. Current Directions in Psychological Science, 9(3), 75-78. http://dx.doi.org/10.1111/1467-8721.00064

Bereiter, C. (2002). Education and mind in the knowledge age. Mahwah, NJ: Lawrence Erlbaum.

Bereiter, C. (2009). Innovation in the absence of principled knowledge: The case of the Wright Brothers. Creativity and Innovation Management, 18(3), 234-241. http://dx.doi.org/10.1111/j.14678691.2009.00528.x

Bereiter, C., \& Scardamalia, M. (1993). Surpassing ourselves: An inquiry into the nature and implications of expertise. Chicago/La Salle, II: Open Court.

Bereiter, C., \& Scardamalia, M. (1998). Beyond Bloom's taxonomy: Rethinking knowledge for the 
(2016). Analytics for knowledge creation: Towards epistemic agency and design-mode thinking. Journal of Learning Analytics, 3(2), 139-163. http://dx.doi.org/10.18608/jla.2016.32.7

knowledge age. In M. Fullan (Ed.), Fundamental change: International handbook of educational change (pp. 5-22). Dordrecht: Springer Netherlands. http://dx.doi.org/10.1007/1-4020-44542__

Bereiter, C., \& Scardamalia, M. (2003). Learning to work creatively with knowledge. In E. De Corte, L. Verschaffel, N. Entwistle, \& J. van Merrienboer (Eds.), Powerful learning environments: Unravelling basic components and dimensions (pp. 55-68). Oxford, UK: Pergamon.

Bereiter, C., \& Scardamalia, M. (2013). Self-organization in conceptual growth: Practical implications. In S. Vosniadou (Ed.), International handbook of research on conceptual change (2nd ed., pp. 504519). New York: Routledge.

Berland, M., Davis, D., \& Smith, C. P. (2015). AMOEBA: Designing for collaboration in computer science classrooms through live learning analytics. International Journal of Computer-Supported Collaborative Learning, 10(4), 425-447. http://dx.doi.org/10.1007/s11412-015-9217-z

Binkley, M., Erstad, O., Herman, J., Raizen, S., Riple, M., Miller-Ricci, M., \& Rumble, M. (2012). Defining $21^{\text {st }}$ century skills. In P. Griffin, B. McGaw, \& E. Care (Eds.), Assessment and Teaching of $21^{\text {st }}$ Century Skills (pp. 17-66). Dordrecht: Springer.

Bloom, B. S. (Ed.). (1956). Taxonomy of educational objectives, Handbook 1: Cognitive domain. New York: David McKay.

Burtis, P. J. (1998). Analytic toolkit for knowledge forum. Centre for Applied Cognitive Science, Ontario Institute for Studies in Education/University of Toronto.

Chen, B. (2014). Visualizing semantic space of online discourse: The Knowledge Forum case. Proceedings of the $4^{\text {th }}$ International Conference on Learning Analytics and Knowledge (LAK '14), 271-272. http://dx.doi.org/10.1145/2567574.2567595

Chen, B. (2016). Fostering scientific understanding and epistemic beliefs through promisingness judgments. Educational Technology Research \& Development. http://dx.doi.org/10.1007/s11423-016-9467-0

Chen, B., \& Hong, H.-Y. (2016). Schools as knowledge building organizations: Thirty years of design research. Educational Psychologist, 266-288. http://dx.doi.org/10.1080/00461520.2016.1175306

Chen, B., Ma, L., Matsuzawa, Y., \& Scardamalia, M. (2015). The development of productive vocabulary in knowledge building: A longitudinal study. In O. Lindwall, P. Häkkinen, T. Koschmann, P. Tchounikine, \& S. Ludvigsen (Eds.), Proceedings of the $11^{\text {th }}$ International Conference on Computer Supported Collaborative Learning: Exploring the Material Conditions of Learning ( $\mathrm{CSCL}$ 2015), (Vol. 1, pp. 443-450). International Society of the Learning Sciences.

Chen, B., Scardamalia, M., \& Bereiter, C. (2015). Advancing knowledge building discourse through judgments of promising ideas. International Journal of Computer-Supported Collaborative Learning, 10(4), 345-366. http://dx.doi.org/10.1007/s11412-015-9225-z

Chen, M.-H., Zhang, J., \& Lee, J. (2013). Making collective progress visible for sustained knowledge building. In N. Rummel, M. Kapur, M. Nathan, \& S. Puntambekar (Eds.), Proceedings of To See the World and a Grain of Sand: Learning across Levels of Space, Time, and Scale (CSCL 2013), (Vol. 1, pp. 81-88). International Society of the Learning Sciences. 
(2016). Analytics for knowledge creation: Towards epistemic agency and design-mode thinking. Journal of Learning Analytics, 3(2), 139-163. http://dx.doi.org/10.18608/jla.2016.32.7

Chuy, M., Resendes, M., Tarchi, C., Chen, B., Scardamalia, M., \& Bereiter, C. (2011). Modi di contribuire ad un dialogo per la ricerca di spiegazioni. QWERTY: Interdisciplinary Journal of Technology, Culture and Education, 6(2), 242-260. Retrieved from http://www.ckbg.org/qwerty/index.php/qwerty/article/viewArticle/114

Claxton, G., Edwards, L., \& Scale-Constantinou, V. (2006). Cultivating creative mentalities: A framework for education. Thinking Skills and Creativity, 1(1), 57-61. http://dx.doi.org/10.1016/j.tsc.2005.11.001

Deakin Crick, R., Huang, S., Ahmed Shafi, A., \& Goldspink, C. (2015). Developing resilient agency in learning: The internal structure of learning power. British Journal of Educational Studies, 63(2), 121-160. http://dx.doi.org/10.1080/00071005.2015.1006574

Desmarais, M. C., \& Baker, R. S. J. d. (2012). A review of recent advances in learner and skill modeling in intelligent learning environments. User Modeling and User-Adapted Interaction, 22(1-2), 9-38. http://dx.doi.org/10.1007/s11257-011-9106-8

Dietz-Uhler, B., \& Hurn, J. E. (2013). Using learning analytics to predict (and improve) student success: A faculty perspective. Journal of Interactive Online Learning, 12(1), 17-26.

Dunbar, K. N. (1995). How scientists really reason: Scientific reasoning in real-world laboratories. In R. J. Sternberg \& J. Davidson (Eds.), The Nature of Insight (pp. 365-395). Cambridge, MA: MIT Press.

Dweck, C. (2006). Mindset: The new psychology of success. New York: Random House LLC.

Elgin, C. Z. (2013). Epistemic agency. Theory and Research in Education, 11(2), 135-152. http://dx.doi.org/10.1177/1477878513485173

Ellis, C. (2013). Broadening the scope and increasing the usefulness of learning analytics: The case for assessment analytics: Colloquium. British Journal of Educational Technology, 44(4), 662-664. http://dx.doi.org/10.1111/bjet.12028

Figner, B., Knoch, D., Johnson, E. J., Krosch, A. R., Lisanby, S. H., Fehr, E., \& Weber, E. U. (2010). Lateral prefrontal cortex and self-control in intertemporal choice. Nature Neuroscience, 13(5), 538-539. http://dx.doi.org/10.1038/nn.2516

Foltz, P., Kintsch, W., \& Landauer, T. K. (1998). The measurement of textual coherence with latent semantic analysis. Discourse Processes, 25(2), 285-307. http://dx.doi.org/10.1080/01638539809545029

Gardner, H. (1994). More on private intuitions and public symbol systems. Creativity Research Journal, 7(3-4), 265-275. http://dx.doi.org/10.1080/10400419409534534

Gloor, P. A. (2005). Swarm creativity: Competitive advantage through collaborative innovation networks. Oxford, UK: Oxford University Press.

Greller, W., \& Drachsler, H. (2012). Translating learning into numbers: A generic framework for learning analytics. Educational Technology \& Society, 15(3), 42-57.

Haas, P. M. (1992). Introduction: Epistemic communities and international policy coordination. International Organization, 46(1), 1. http://dx.doi.org/10.1017/S0020818300001442

Hacker, D. J., Dunlosky, J., \& Graesser, A. C. (2009). Handbook of metacognition in education. London: Routledge.

Hakkarainen, K. (2003). Progressive inquiry in a computer-supported biology class. Journal of Research in 
(2016). Analytics for knowledge creation: Towards epistemic agency and design-mode thinking. Journal of Learning Analytics, 3(2), 139-163. http://dx.doi.org/10.18608/jla.2016.32.7

Science Teaching, 40(10), 1072-1088. http://dx.doi.org/10.1002/tea.10121

Hatano, G., \& Inagaki, K. (1986). Two courses of expertise. In H. W. Stevenson, H. Azuma, \& K. Hakuta (Eds.), Child development and education in Japan. A series of books in psychology (pp. 262-272). New York, NY, US: W H Freeman/Times Books/Henry Holt \& Co.

Hewitt, J. (2001). Beyond threaded discourse. International Journal of Educational Telecommunications, $7(3), 207-221$.

Hong, H.-Y., \& Scardamalia, M. (2014). Community knowledge assessment in a knowledge building environment. Computers \& Education, 71, 279-288. http://dx.doi.org/10.1016/j.compedu.2013.09.009

Hong, H.-Y., \& Sullivan, F. R. (2009). Towards an idea-centered, principle-based design approach to support learning as knowledge creation. Educational Technology Research and Development, 57(5), 613-627. http://dx.doi.org/10.1007/s11423-009-9122-0

Kamii, C. (1984). Autonomy: The aim of education envisioned by Piaget. The Phi Delta Kappan, 65(6), 410-415.

Knight, S., Buckingham Shum, S., \& Littleton, K. (2014). Epistemology, assessment, pedagogy: Where learning meets analytics in the middle space. Journal of Learning Analytics, 1(2), 23-47. Retrieved from https://epress.lib.uts.edu.au/journals/index.php/JLA/article/view/3538

Krathwohl, D. R. (2002). A revision of Bloom's taxonomy: An overview. Theory Into Practice, 41(4), 212218. http://dx.doi.org/10.1207/s15430421tip4104_2

Lawless, K. A., Mills, R., \& Brown, S. W. (2002). Children's hypertext navigation strategies. Journal of Research on Technology in Education, 34(3), 274-284. http://dx.doi.org/10.1080/15391523.2002.10782349

Long, P., \& Siemens, G. (2011). Penetrating the fog: Analytics in learning and education. Educause Review, 46(5), 30-32.

Ma, L., Matsuzawa, Y., Chen, B., \& Scardamalia, M. (2016). Community knowledge, collective responsibility: The emergence of rotating leadership in three knowledge building communities. In Ch.-K. Looi, J. Polman, U. Cress, P. Reimann (Eds.), Proceedings of the International Conference on Learning Sciences: Transforming Learning, Empowering Learners (ISLS 2016), (Vol.1, p. 615622). Singapore: The International Society of the Learning Sciences. Retrieved from https://www.isls.org/icls/2016/docs/ICLS2016_Volume_1_30June2016.pdf

Morrison, D., \& Collins, A. (1996). Epistemic fluency and constructivist learning environments. In B. G. Wilson (Ed.), Constructivist learning environments: Case studies in instructional design (pp. 107119). Englewood Cliffs, NJ: Educational Technology Publications, Inc.

National Academy of Engineering. (2015). Educate to Innovate: Factors that Influence Innovation. Washington, DC: The National Academies Press. http://dx.doi.org/10.17226/21698

Olguin, D. O., Gloor, P. A., \& Pentland, A. S. (2009). Capturing individual and group behavior with wearable sensors. Proceedings of the 2009 AAAl Spring Symposium on Human Behavior Modeling (Vol. 9). Stanford University, Palo Alto, California.

OECD (Organisation for Economic Co-operation and Development). (2004). Innovation in the knowledge economy: Implications for education and learning. Paris: OECD Publishing. 
(2016). Analytics for knowledge creation: Towards epistemic agency and design-mode thinking. Journal of Learning Analytics, 3(2), $139-163$. http://dx.doi.org/10.18608/jla.2016.32.7

\section{http://dx.doi.org/10.1787/9789264105621-en}

Oshima, J., Oshima, R., \& Matsuzawa, Y. (2012). Knowledge building discourse explorer: A social network analysis application for knowledge building discourse. Educational Technology Research and Development, 60(5), 903-921. http://dx.doi.org/10.1007/s11423-012-9265-2

Perkins, D. N., \& Grotzer, T. A. (2000). Models and moves: Focusing on dimensions of causal complexity to achieve deeper scientific understanding. Paper presented at the 2000 American Educational Research Association Annual Meeting, 24-28 April 2000, New Orleans, LA.

Piaget, J. (1972). A structural foundation for tomorrow's education. Prospects, 2(1), 12-27. http://dx.doi.org/10.1007/BF02195648

Prinsloo, P., Slade, S., \& Galpin, F. (2012). Learning analytics: Challenges, paradoxes and opportunities for mega open distance learning institutions. Proceedings of the $2^{\text {nd }}$ International Conference on Learning Analytics and Knowledge (LAK '12), 130-133. http://doi.org/10.1145/2330601.2330635

Resendes, M., Scardamalia, M., Bereiter, C., Chen, B., \& Halewood, C. (2015). Group-level formative feedback and metadiscourse. International Journal of Computer-Supported Collaborative Learning, 10(3), 309-336. http://dx.doi.org/10.1007/s11412-015-9219-x

Rittel, H. W. J., \& Webber, M. M. (1973). Dilemmas in a general theory of planning. Policy Sciences, 4(2), 155-169. http://dx.doi.org/10.1007/BF01405730

Rosé, C., Wang, Y.-C., Cui, Y., Arguello, J., Stegmann, K., Weinberger, A., \& Fischer, F. (2008). Analyzing collaborative learning processes automatically: Exploiting the advances of computational linguistics in CSCL. International Journal of Computer-Supported Collaborative Learning, 3(3), 237-271. http://dx.doi.org/10.1007/s11412-007-9034-0

Ruipérez-Valiente, J. A., Muñoz-Merino, P. J., Leony, D., \& Delgado Kloos, C. (2014). ALAS-KA: A learning analytics extension for better understanding the learning process in the Khan Academy platform. Computers in Human Behavior. http://dx.doi.org/10.1016/j.chb.2014.07.002

Scardamalia, M. (2002). Collective cognitive responsibility for the advancement of knowledge. In B. Smith (Ed.), Liberal education in a knowledge society (pp. 67-98). Chicago, IL: Open Court.

Scardamalia, M., \& Bereiter, C. (1991). Higher levels of agency for children in knowledge building: A challenge for the design of new knowledge media. Journal of the Learning Sciences, 1(1), 37-68. http://doi.org/10.1207/s15327809jls0101_3

Scardamalia, M., \& Bereiter, C. (2003). Knowledge building. In J. W. Guthrie (Ed.), Encyclopedia of education (2nd ed., Vol. 17, pp. 1370-1373). New York: Macmillan Reference.

Scardamalia, M., \& Bereiter, C. (2014). Knowledge building and knowledge creation: Theory, pedagogy, and technology. In R. K. Sawyer (Ed.), Cambridge Handbook of the Learning Sciences. New York: Cambridge University Press.

Scardamalia, M., Bransford, J. D., Kozma, B., \& Quellmalz, E. (2012). New assessments and environments for knowledge building. In Assessment and Teaching of $21^{\text {st }}$ Century Skills (pp. 231-300). Springer. http://dx.doi.org/10.1007/978-94-007-2324-5_5

Schwartz, D. L., \& Arena, D. (2013). Measuring what matters most: Choice-based assessments for the digital age. Cambridge, MA: The MIT Press.

Segedy, J. R., Kinnebrew, J. S., \& Biswas, G. (2015). Using coherence analysis to characterize self- 
(2016). Analytics for knowledge creation: Towards epistemic agency and design-mode thinking. Journal of Learning Analytics, 3(2), 139-163. http://dx.doi.org/10.18608/jla.2016.32.7

regulated learning behaviours in open-ended learning environments. Journal of Learning Analytics, 2(1), 13-48. Retrieved from

https://epress.lib.uts.edu.au/journals/index.php/JLA/article/view/4129

Sfard, A. (1998). On two metaphors for learning and the dangers of choosing just one. Educational Researcher, 27(2), 4-13. http://dx.doi.org/10.3102/0013189X027002004

Shafir, E., Simonson, I., Tversky, A. (1993). Reason-based choice. Cognition, 49(1-2), 11-36.

Slade, S., \& Prinsloo, P. (2013). Learning analytics: Ethical issues and dilemmas. American Behavioral Scientist, 57(10), 1510-1529. http://dx.doi.org/10.1177/0002764213479366

Stahl, G. (2013). Learning across levels. International Journal of Computer-Supported Collaborative Learning, 8(1), 1-12. http://dx.doi.org/10.1007/s11412-013-9169-0

Subotzky, G., \& Prinsloo, P. (2011). Turning the tide: A socio-critical model and framework for improving student success in open distance learning at the University of South Africa. Distance Education, 32(2), 177-193. http://dx.doi.org/10.1080/01587919.2011.584846

Sun, W., Zhang, J., Jin, H., \& Lyu, S. (2014). Analyzing Online Knowledge-Building Discourse Using Probabilistic Topic Models. In J. L. Polmand, E. A. Kyza, K. O’Neill, \& I. Tabak, W. R. Penual, A. S. Jurow, K. O'Connor, T. Lee, L. D'Amico (Eds.), Proceedings of the International Conference of the Learning Sciences: Learning and becoming in practice (ICLS 2014), (Vol. 2, pp. 823-830). Boulder, CO: International Society of the Learning Sciences.

Sun, W., Zhang, J., Jin, H., \& Lyu, S. (2014). Analyzing online knowledge building discourse using probabilistic topic models. In J. Polman, E. Kyza, K. O’Neill, \& I. Tabak W. R. Penual, A. S. Jurow, K. O'Connor, T. Lee, L. D'Amico (Eds.), Proceedings of the International Conference of the Learning Sciences: Learning and becoming in practice (ICLS 2014), (Vol. 2, pp. 823-830). Boulder, CO. International Society of the Learning Sciences.

Suthers, D. D., Vatrapu, R., Medina, R., Joseph, S., \& Dwyer, N. (2008). Beyond threaded discussion: Representational guidance in asynchronous collaborative learning environments. Computers \& Education, 50(4), 1103-1127. http://dx.doi.org/10.1016/j.compedu.2006.10.007

Suthers, D., \& Verbert, K. (2013). Learning analytics as a "middle space." Proceedings of the $3^{\text {rd }}$ International Conference on Learning Analytics and Knowledge (LAK '13), 1-4. http://doi.org/10.1145/2460296.2460298

Teplovs, C., Donoahue, Z., Scardamalia, M., \& Philip, D. (2007). Tools for concurrent, embedded, and transformative assessment of knowledge building processes and progress. In C. A. Chinn, G. Erkens, S. Puntambekar (Eds.), Proceedings of the $8^{\text {th }}$ International Conference on ComputerSupported Collaborative Learning (CSCL 2007), (Vol. 1, pp. 721-723). International Society of the Learning Sciences.

Teplovs, C., \& Fujita, N. (2009). Determining curricular coverage of student contributions to an online discourse environment: Using latent semantic analysis to construct differential term clouds. In C. O'Malley, D. Suthers, P. Reimann, A. Dimitracopoulou (Eds.), Proceedings of the $9^{\text {th }}$ International Conference on Computer-Supported Collaborative Learning (CSCL 2009), (Vol. 2, pp. 165-167). International Society of the Learning Sciences.

Thomas, D., \& Brown, J. S. (2011). A new culture of learning: Cultivating the imagination for a world of 
(2016). Analytics for knowledge creation: Towards epistemic agency and design-mode thinking. Journal of Learning Analytics, 3(2), 139-163. http://dx.doi.org/10.18608/jla.2016.32.7

constant change. Lexington, KY: CreateSpace.

van Aalst, J., Mu, J., \& Yang, Y. (2016). Formative assessment of computer-supported collaborative learning and knowledge building. In P. Reimann, S. Bull, M. Kickmeier-Rust, R. Vatrapu, \& B. Wasson (Eds.), Measuring and visualizing learning in the information-rich classroom (pp. 154166). New York: Routledge.

Wertheimer, M., \& Wertheimer, M. (1959). Productive thinking. New York: Harper.

Winne, P. H. (1995). Inherent details in self-regulated learning. Educational Psychologist, 30(4), 173-187. http://dx.doi.org/10.1207/s15326985ep3004_2

Winne, P. H., \& Hadwin, A. F. (2013). nStudy: Tracing and supporting self-regulated learning on the Internet. In R. Azevedo \& V. Aleven (Eds.), International Handbook of Metacognition and Learning Technologies (pp. 293-308). New York: Springer. http://dx.doi.org/10.1007/978-14419-5546-3_20

Wise, A. F. (2014). Designing pedagogical interventions to support student use of learning analytics. Proceedings of the $4^{\text {th }}$ International Conference on Learning Analytics and Knowledge (LAK '14), 203-211. http://dx.doi.org/10.1145/2567574.2567588

Zhang, J., Chen, M.-H., Chen, J., \& Mico, T. F. (2013). Computer-supported metadiscourse to foster collective progress in knowledge-building communities. In N. Rummel, M. Kapur, M. Nathan, \& S. Puntambekar (Eds.), Proceedings of To See the World and a Grain of Sand: Learning across Levels of Space, Time, and Scale (CSCL 2013), (Vol.1, pp. 197-200). International Society of the Learning Sciences.

Zhang, J., Chen, M.-H., Tao, D., Sun, Y., Lee, J., \& Judson, D. (2015). Fostering sustained knowledge building through metadiscourse aided by the Idea Thread Mapper. In O. Lindwall, P. Häkkinen, T. Koschmann, P. Tchounikine, \& S. Ludvigsen (Eds.), Proceedings of the $11^{\text {th }}$ International Conference on Computer Supported Collaborative Learning: Exploring the Material Conditions of Learning (CSCL 2015), (Vol. 1, pp. 166-173). International Society of the Learning Sciences.

Zhang, J., Scardamalia, M., Lamon, M., Messina, R., \& Reeve, R. (2007). Socio-cognitive dynamics of knowledge building in the work of 9- and 10-year-olds. Educational Technology Research and Development, 55(2), 117-145. http://dx.doi.org/10.1007/s11423-006-9019-0

Zhang, J., Scardamalia, M., Reeve, R., \& Messina, R. (2009). Designs for collective cognitive responsibility in knowledge-building communities. Journal of the Learning Sciences, 18(1), 7-44. http://dx.doi.org/10.1080/10508400802581676 